\title{
Optimization of Parking Lot in the Forms of Parallelogram and Right Triangle for Cars and Motorbikes
}

\author{
Widiawati Putri, Ihda Hasbiyati", Moh Danil Hendry Gamal \\ Department of Mathematics, University of Riau, Pekanbaru, Indonesia \\ Email address: \\ widiawati.putry@yahoo.com (W. Putri), ihdahasbiyati@gmail.com (I. Hasbiyati), mdhgamal@unri.ac.id (M. D. H. Gamal) \\ ${ }^{*}$ Corresponding author
}

\section{To cite this article:}

Widiawati Putri, Ihda Hasbiyati, Moh Danil Hendry Gamal. Optimization of Parking Lot in the Forms of Parallelogram and Right Triangle for Cars and Motorbikes. Mathematical Modelling and Applications. Vol. 4, No. 4, 2019, pp. 64-71. doi: 10.11648/j.mma.20190404.12

Received: November 21, 2019; Accepted: December 18, 2019; Published: December 30, 2019

\begin{abstract}
Parking lots are elements that affect the transportation system. Placement of the wrong parking lot, such as on a roadside, causes congestion. One way to overcome this is to provide safe and efficient parking. This article discusses the optimization of parking lots in the form of parallelograms and right triangles for cars and motorbikes. The shape of the parallelogram land is formed in two ways namely directly and separately, the landform separately consists of the form of two right triangles and rectangles. The initial step in this discussion is to make a design on the parking lot and assumptions that correspond to the shape of the land. The design of parking lots in this article consists of three designs, namely land in the form of parallelograms, right triangles and rectangles. Furthermore, a mathematical model was built for each land design. The method used for the calculation of mathematical models for each design is the linear programming method and is calculated using LINGO software. The results obtained are the optimum number of car and motorbikes vehicles for each land design. In this article, the optimal results for car vehicles with land in the form of parallelograms formed directly are 1110 vehicles, furthermore the form of parallelograms formed separately are 1295 vehicles. These results indicate that the two forms are more optimal than the separated forms. Then, for the form of a right triangle gives optimal results $491 \mathrm{car}$ vehicles. The next vehicle is a motorbikes, the optimal result for motorbikes with land in the form of a parallelogram that is formed directly is 11969 vehicles, then the shape of the parallelogram is formed separately there are 15440 vehicles. Then, to form a right triangle give optimal results 6163 motorbikes vehicles.
\end{abstract}

Keywords: Parking Lot Optimization, Parking Lot Design, Linear Programming, Parallelogram Parking Lots, Right Triangle Parking Lots

\section{Introduction}

The transportation system is a system with various kinds of facilities. One of the transportation system facilities is the parking lot. The Indonesian Directorate General of Transportation has decided that there are procedures for parking vehicles in public places, roads and parking lots. How to park using the body of the road, what so called street parking, has certain ways so that it does not interfere with the road traffic and does not cause traffic jams. Therefore, to reduce the effects of wrong parking which will cause new problems, it is necessary to provide parking space for parking vehicles, so that other activities will run safely without obstacles. Somethings that need to be considered in the provision of parking lots are service, parking time and distance of travel from the parking lot to the destination [13].

According to the Indonesian Directorate General of Transportation, a parking lot is a vehicle parking facility provided to park a vehicle in a temporary period [4]. Parking lots come in various shapes, designs and sizes. The greater the size of the parking lot provided the more vehicles could park. Land with a good design and proper circulation and placement of vehicles is an ideal parking area because the parking lot meets the criteria as a secure parking area.

There are various forms of parking lots, such as rectangles, squares, triangles, up to irregular shapes to match the available land. Therefore, the duty of the parking attendant is to design the contents of the parking lot in accordance with the measurements of the vehicle to be accommodated, as well as the vehicle's circulation settings in it so that the parking lot 
meets the desired criteria.

Along with the times, the number of vehicles is increasing so it also affects the level of parallelogram parking space for vehicles. Therefore, the authors are interested in discussing a form of parking lot that is rarely used by parking attendants, namely the form of a parallelogram by continuing the discussion of Hasbiyati et al. [6]. The parking lot in the form of parallelograms in this discussion is applied to vehicles of various types of cars and motorbikes. The shape of the parking lot in the form of a parallelogram is made with two comparisons, namely the form of a parallelogram directly and the form of a parallelogram separately.

Much research has been done for parking lots. All aims to optimize parking. Previous research that has been done is a discussion about optimizing available parking lots based on an analysis of parking needs and identification of parking problems. This discussion was implemented on the Panglima Polem road in Banda Aceh, Indonesia [7]. Furthermore, with the same discussion but a different case, namely in Dataran Mawar, UiTM Shah Alam, Malaysia. This study compared three parking designs such as perpendicular parking, parallel parking, and diagonal parking (corner) [2].

A parking lot design will be formed properly if in the manufacturing process has been well planned. The discussion that has been done is about planning to design a parking space in a parking lot with the aim to get optimal results [3]. In addition to planning, the method used also influences the results obtained. Discussion on optimizing the parking area using the linear program method has been carried out with 3 cases, namely the case with a vehicle located near the wall in the parking lot where there are 2 circulation at the entrance and exit of the vehicle, the second case with one circulation, while the third case is distinguished from vehicles that are not adjacent to the wall [1]. Research with the same method has also been carried out, it's just different at the place of application, namely at the Tamale-Bolgatanga truck station in Ghana [8].

The times have influenced the availability of parking lots, so the shape of the parking lot adjusts the available land. Research that has been done for parking lots is a discussion of mathematical models for parking lots in the form of isosceles triangles and equilateral triangles [10]. The types of vehicles modeled in their discussion are motorbikes and cars and the results obtained are the optimal number of vehicles and the vehicle's parking angle. The same research was also carried out with a different form, namely the form of a parallelogram by using a linear program for car vehicles using the concept of area [6].

\section{Theoretical Background}

\subsection{Linear Programming}

Linear programming is a mathematical model in allocating limited resources to achieve a goal such as maximizing profits and minimizing costs. The problems that are widely applied in this linear program are problems such as economic, industrial, military, social and so on. Linear programs in the application of real cases first model in the form of mathematical models by determining the objective function and problem constraints. The stages in completing the optimization of the linear program include determining the variables to be used, creating objective functions and formulating constraints and then solving the problem with the graphical approach or the simplex method. The graphical method is used to solve linear program problems if the variable of the problem is no more than two variables while for variables that are more than two methods used are the simplex method. General form of a mathematical model of a linear program is as follows:

$$
\max z=c_{1} x_{1}+c_{2} x_{2}+\cdots+c_{n} x_{n}
$$

subject to

$$
\begin{gathered}
a_{11} x_{1}+a_{12} x_{2}+\cdots+a_{1 n} x_{n} \leq b_{1} \\
a_{21} x_{1}+a_{22} x_{2}+\cdots+a_{2 n} x_{n} \leq b_{2} \\
a_{n 1} x_{1}+a_{m 2} x_{2}+\cdots+a_{m n} x_{n} \leq b_{m} \\
x_{1} \geq 0, x_{2} \geq 0, \cdots x_{n} \geq 0
\end{gathered}
$$

with $x_{1}, x_{2}, \cdots, x_{n}$ are decision variable. The number of decision variables depends on the number of activities or activities to achieve the goal. Furthermore, $c_{1}, c_{2}, \cdots, c_{n}$ is the contribution of each decision variable to the goal or can be called the coefficient of the objective function. Symbols $a_{11}, \cdots, a_{1 n}, \cdots, a_{m n}$ are the use per unit of decision variables towards resources that limit or also the coefficient of constraint functions. Then, $b_{1}, b_{2}, \cdots, b_{n}$ indicate the sum of each of the available resources. The number of constraint functions depends on the number of limited resources. For the inequality at the end of the equation above, $x_{1}, x_{2}, \cdots, x_{n} \geq 0$ indicates the non-negative boundary.

\subsection{Parking Space Unit (PSU)}

Parking is a situation where the vehicle does not move or stop temporarily. Parking can be done in a parking lot or land that has been provided or parked on a road or roadside. The road is a place designated for public traffic, so that if used for public facilities traffic activities will be disrupted and will cause congestion. To prevent traffic jams, parking must be done at the designated place and in accordance with the parking space units in accordance with the provisions of the Ministry of Transportation. Parking Space Unit is a measure of effective parking area for vehicles such as passenger cars, motorbikes, including free spaces for vehicles to open and close doors. Before the measurements of the Parking Space Unit are formed, the first thing to do is to make a general 
design of the parking lot and the layout of the vehicle to be parked.

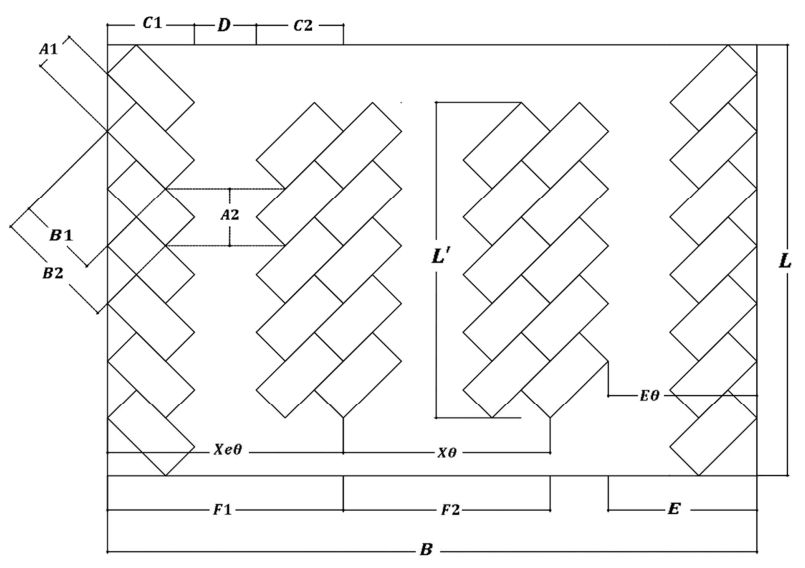

Figure 1. Parking Lot Design.

Figure 1 is a development design of the Abdelfatah and Taha designs [1]. Assuming the vehicle layout in Figure 1 is with three possible vehicle lines, namely, first is located in the full exterior area $(\mathrm{Xe} \theta)$ which is the width from the wall to the end of the vehicle boundary in the parking line after the first aisle or in the picture symbolized $F 1$. Secondly, it is located in the full interior area $(X \theta)$ which is the width of the parking lot with two parking lines separated by aisles or symbolized $F 2$. Furthermore, the third possibility, namely in the exterior area $(E \theta)$ is the width of the wall plus the width of the alley in the parking lot or in the picture symbolized by $E$. The following table 1 (Unit of Private Car Parking Space) and Table 2 (Unit of Motorcycle Parking Space) is the size of Figure 1 that matches the standard size set by the Department of Transportation.

\subsection{Parking Optimization Model}

Figure 1 is one of the parking design drawings discussed. Figure 1 is also a design that represents a general description of the parking design. The purpose of Abdelfatah and Taha in the design that has been made is the optimization of the number of vehicles, so that the number of vehicles is symbolized by $N$.

Table 1. Unit of Private Car Parking Space.

\begin{tabular}{|c|c|c|c|c|c|c|}
\hline \multirow{2}{*}{ Dimensions (meters) } & \multirow{2}{*}{ Symbol } & \multicolumn{5}{|c|}{ Corner } \\
\hline & & 30 & 45 & 60 & 75 & 90 \\
\hline Car width & $A 1$ & 2.50 & 2.50 & 2.50 & 2.50 & 2.50 \\
\hline Car width when tilted & $A 2$ & 5.00 & 3.54 & 2.89 & 2.59 & 2.50 \\
\hline Car length & $B 1$ & 5.00 & 5.00 & 5.00 & 5.00 & 5.00 \\
\hline Car length when tilted & $B 2$ & 9.33 & 7.50 & 6.44 & 5.67 & 5.00 \\
\hline The length of the vehicle from the wall to the end of the vehicle & $C 1$ & 4.67 & 5.30 & 5.58 & 5.48 & 5.00 \\
\hline The length of the vehicle from the curb to the end of the vehicle & $C 2$ & 3.58 & 4.42 & 4.96 & 5.15 & 5.00 \\
\hline \multirow[t]{2}{*}{ Length from wall to parking line boundary after alley (exterior) } & $E$ & 8.17 & 9.05 & 10.08 & 11.48 & 12.00 \\
\hline & $F 1$ & 11.75 & 13.47 & 15.04 & 16.63 & 17.00 \\
\hline \multirow{2}{*}{$\begin{array}{l}\text { Length from wall to end of vehicle boundary on the middle } \\
\text { parking half row (full exterior) } \\
\text { Interior }\end{array}$} & $F 2$ & 10.66 & 12.59 & 14.42 & 16.30 & 17.00 \\
\hline & $F 3$ & 7.16 & 8.84 & 9.92 & 10.3 & 10.00 \\
\hline
\end{tabular}

Table 2. Unit of Motorbikes Parking Space.

\begin{tabular}{|c|c|c|c|c|c|c|}
\hline \multirow{2}{*}{ Dimensions (meters) } & \multirow{2}{*}{ Symbol } & \multicolumn{5}{|c|}{ Corner } \\
\hline & & 30 & 45 & 60 & 75 & 90 \\
\hline Motor width & $A 1$ & 0.70 & 0.70 & 0.70 & 0.70 & 0.70 \\
\hline Motor width when tilted & $A 2$ & 1.40 & 0.99 & 0.81 & 0.72 & 0.70 \\
\hline Motor length & $B 1$ & 2.00 & 2.00 & 2.00 & 2.00 & 2.00 \\
\hline Motor length when tilted & $B 2$ & 3.21 & 2.70 & 2.40 & 2.19 & 2.00 \\
\hline The length of the vehicle from the wall to the end of the vehicle & $C 1$ & 1.61 & 1.91 & 2.08 & 2.11 & 2.00 \\
\hline The length of the vehicle from the curb to the end of the vehicle & $C 2$ & 1.30 & 1.66 & 1.91 & 2.02 & 2.00 \\
\hline \multirow[t]{2}{*}{ Length from wall to parking line boundary after alley (exterior) } & $E$ & 3.21 & 3.51 & 3.68 & 3.71 & 3.60 \\
\hline & $F 1$ & 4.51 & 5.17 & 5.59 & 5.73 & 5.60 \\
\hline \multirow{2}{*}{$\begin{array}{l}\text { Length from wall to end of vehicle boundary on the middle } \\
\text { parking half row (full exterior) } \\
\text { Interior }\end{array}$} & $F 2$ & 4.20 & 4.92 & 5.42 & 5.64 & 6.60 \\
\hline & $F 3$ & 2.6 & 3.32 & 3.82 & 4.04 & 4.00 \\
\hline
\end{tabular}

The decision variables for the mathematical model in Figure 1 are as follows: $\theta$.

$X e \theta=$ number of lines in the full external area with angle

$X \theta=$ number of lines in the interior area filled with angle $\theta$.
$E \theta=$ number of lines in the external area with angle $\theta$. Ne$\theta=$ number of vehicles in the full external area with angle $\theta$.

$N \theta=$ number of vehicles in an interior area full of angle $\theta$. $N E E \theta=$ number of vehicles in the exterior area with an 
angle $\theta$.

Next, the design mathematical model in Figure 1 is as follows:

$$
\max z=\sum_{\theta=30,45,60,75,90} N e \theta+N \theta+N E E \theta
$$

subject to

$$
\begin{gathered}
F 1 X e \theta+F 2 X \theta+F 3 E \theta \leq W \\
A 2 N e \theta-L X e \theta-L^{\prime} X e \theta \leq 0 \\
A 2 N \theta-2 L^{\prime} X \theta \leq 0
\end{gathered}
$$

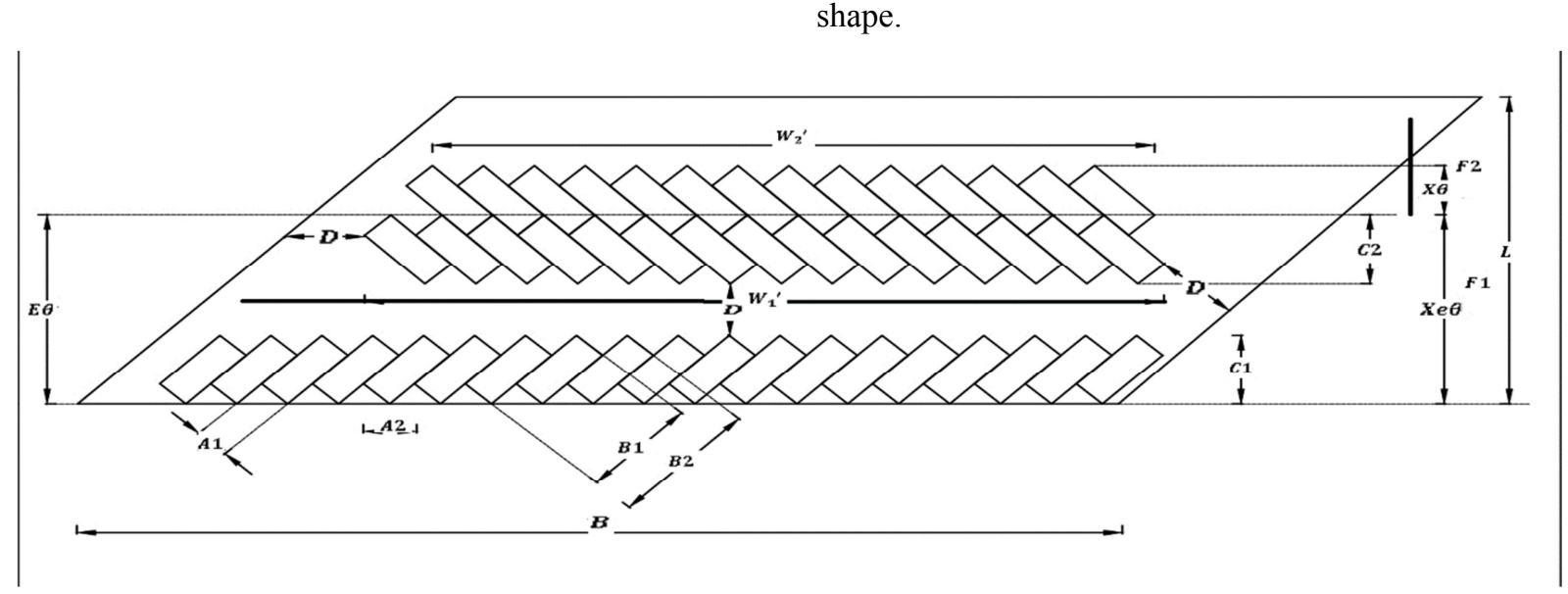

Figure 2. Design parallelogram parking lots.

Furthermore, to find out the capacity in the land depicted in Figure 2, then it is presented in the form of a mathematical model. Linear programing and LINGO software are used to help the optimization calculations. In Figure 2 there are new variables namely $W_{1}{ }^{\prime}$ and $W_{2}{ }^{\prime}$ which are the length of the first and second inner parking lines for parallelogram land. Then the land size for parallelograms is 190 meters wide and 130 meters high, while for the right triangle the base is 100 meters and the height is 130 meters and the rectangle is 90 meters wide and 130 meters.

The mathematical model for Figure 2, is given by

$$
\max z=\sum_{\theta=30,45,60,75,90} 2 \mathrm{Ne} \theta+2 \mathrm{~N} \theta
$$

subject to

$$
\begin{gathered}
2 F 1 X e \theta+2 F 2 X \theta \leq L \\
A 2 N e \theta-W X e \theta-W_{1}{ }^{\prime} X e \theta \leq 0 \\
A 2 N \theta-W_{1}{ }^{\prime} X \theta-W_{2}{ }^{\prime} X \theta \leq 0
\end{gathered}
$$

$$
\sum_{\theta=30,45,60,75,90} X e \theta+E \theta \leq 2
$$

Ne$\theta, N \theta, N E E \theta, X e \theta, X \theta, E \theta \geq 0$

\section{Result and Discussion}

This section discusses the optimization of parking lots in the form of parallelograms formed in two ways, namely the form of parallelograms and the forms of parallelograms formed separately. The first discussion is optimization of parking space in the form of parallelogram. Figure 2 gives a parking lot design in the form of parallelogram with general shape. 


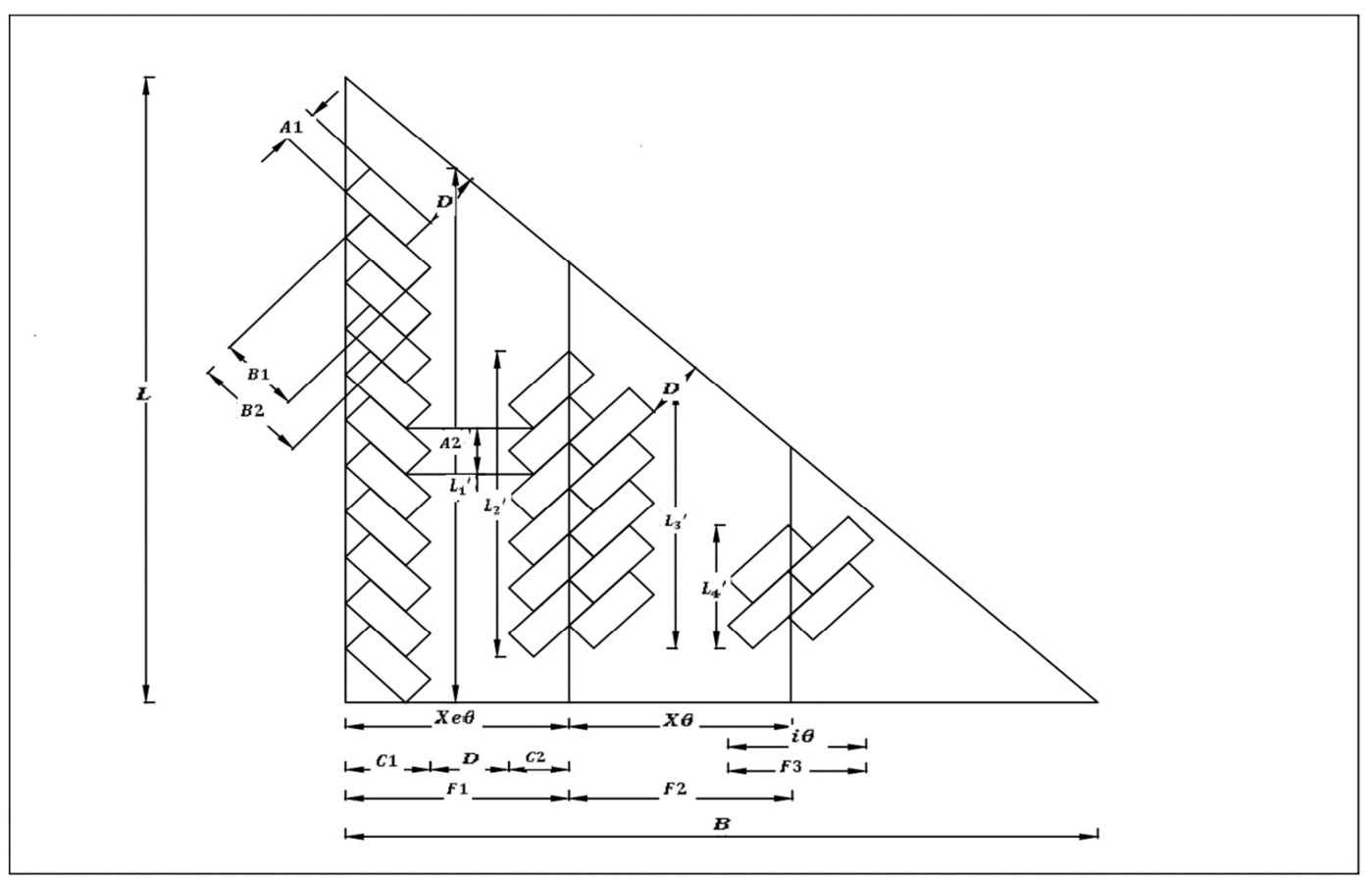

Figure 3. Right triangle shaped land design.

Figure 3 is a picture of the land design in the form of a right triangle. The latest variable and dimension is $F 3$ which is the parking width for the two adjacent parking rows, also known as interior. Next, $L_{1}{ }^{\prime}, L_{2}{ }^{\prime}, L_{3}{ }^{\prime}, L_{4}{ }^{\prime}$ which is the length or height of the interior of the first to the fourth plot of the middle of a right triangle.

The mathematical model for the design in Figure 3 is given by

$$
\max z=\sum_{\theta=30,45,60,75,90} N e \theta+N \theta+N i \theta
$$

subject to

$$
\begin{gathered}
F 1 X e \theta+F 2 X \theta+F 3 i \theta \leq B \\
A 2 N e \theta-L_{1}{ }^{\prime} X e \theta-L_{2}{ }^{\prime} X e \theta \leq 0 \\
A 2 N \theta-L_{3}{ }^{\prime} X \theta-L_{4}{ }^{\prime} X \theta \leq 0 \\
A 2 N i \theta-L_{4}{ }^{\prime} i \theta \leq 0 \\
\sum_{\theta=30,45,60,75,90} X e \theta \leq 1 \\
\sum_{\theta=30,45,60,75,90} i \theta \leq 1
\end{gathered}
$$

$$
N e \theta, N \theta, N i \theta, X e \theta, X \theta, i \theta \geq 0
$$

The decision variables in this Figure 3 model are $\mathrm{Ne} \theta, \mathrm{N} \theta, \mathrm{Ni} \theta, \mathrm{Xe} \theta, \mathrm{X} \boldsymbol{\theta}, i \boldsymbol{\theta}$. Next, $i \boldsymbol{\theta}$ is the number of lines in the interior area with an angle $\theta$ and $N i \theta$ is the number of vehicles in the interior area with an angle $\theta$. The objective function of the model is to maximize the number of vehicles in the full exterior, interior full. and interior. Next the rectangular design is as follows:

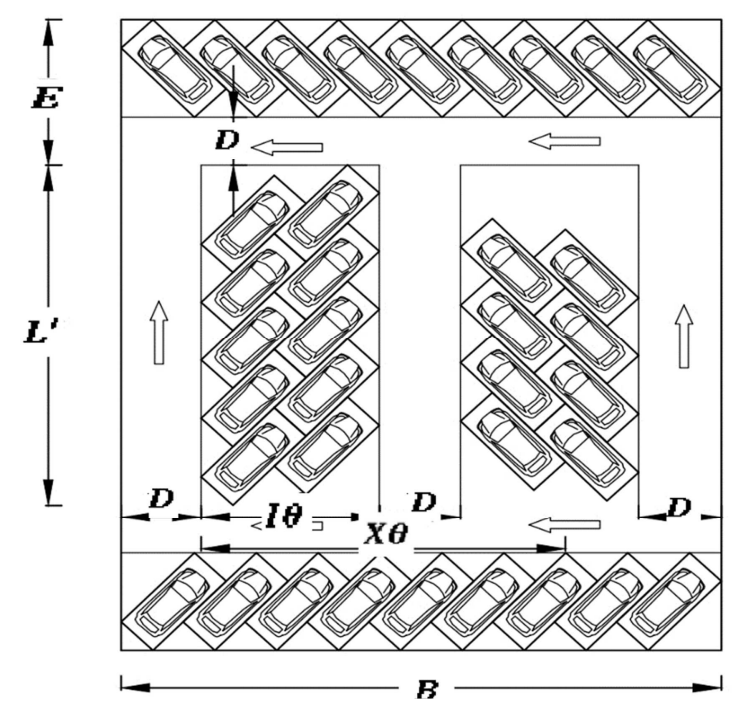

Figure 4. Rectangular land design.

The decision variables in this Figure 4 model are $N E E \theta, N \theta, N i \theta, E \theta, X \theta, i \theta$. The objective function of the model is to maximize the number of vehicles in the exterior, full interior, and interior. The mathematical model for the design in Figure 4 is given as

$$
\max z=\sum_{\theta=30,45,60,75,90} N E E \theta+N \theta+N i \theta
$$

subject to 


$$
\begin{gathered}
2 E E \theta+L^{\prime} i \theta \leq L \\
F 3 i \theta+F 2 X \theta \leq B \\
A 2 N E E \theta-B^{\prime} E \theta \leq 0 \\
A 2 N \theta-2 L^{\prime} X \theta \leq 0 \\
A 2 N i \theta-L^{\prime} i \theta \leq 0 \\
\sum_{\theta=30,45,60,75,90} E \theta \leq 2 \\
N E E \theta, N \theta, N i \theta, E \theta, X \theta, i \theta \geq 0
\end{gathered}
$$

The second land is in the form of parallelograms formed from two right angles and rectangles, so that the optimal results obtained from the mathematical model in equations (18) to (25) are added to the optimal results in equations (26) to (33). Next, the coefficients in all equations are replaced by the dimensions in Table 1 and Table 2. Figure 3 produces 491 vehicle vehicles, with a parking angle of 75 degrees for a full exterior area of 89 vehicles. The full interior area also forms a 75-degree parking angle with 402 cars and there are 5 parking lines formed. Then, for motorcycle vehicles there are
6163 vehicles. The full exterior parking angle is 90 degrees with 353 vehicles and there are 5810 vehicles with a 75 degree angle for 16 lines in the full interior area.

The rectangular area using the model in equations (26) to (33) produces the number of vehicles for cars, 313 vehicles. The angle formed in the full interior area is a 90 degree angle with 1 row and 32 vehicles. While in the interior it forms a 60 degree angle with 5 lines and 217 vehicles. Then, in the full exterior area is a 90 degree angle with 2 lines and 64 vehicles.

Furthermore, for motorbike vehicles there are 3114 vehicles. The angle formed in the full exterior area is a 90 degree angle with 2 lines and 248 vehicles. Whereas in the full interior area it forms a 90 degree angle with 15 lines and 2701 vehicles. Then, the angle formed in the interior area is a 90 degree angle with 1 row and 165 vehicles. The shape of the second parallelogram is a

\begin{tabular}{|c|c|c|c|}
\hline \multirow{2}{*}{ Decision variable } & \multicolumn{3}{|l|}{ Landform } \\
\hline & Parallelogram (direct) & Parallelogram (two right triangles and rectangles) & Right triangle \\
\hline Ne30 & 0 & 0 & 0 \\
\hline $\mathrm{Ne} 45$ & 0 & 0 & 0 \\
\hline Ne60 & 0 & 0 & 0 \\
\hline $\mathrm{Ne} 75$ & 0 & 178 & 89 \\
\hline$N e 90$ & 293 & 64 & 0 \\
\hline N30 & 0 & 0 & 0 \\
\hline N45 & 0 & 0 & 0 \\
\hline$N 60$ & 262 & 804 & 402 \\
\hline N75 & 0 & 0 & 0 \\
\hline$N 90$ & 0 & 32 & 0 \\
\hline NEE30 & 0 & 0 & 0 \\
\hline NEE45 & 0 & 0 & 0 \\
\hline NEE60 & 0 & 0 & 0 \\
\hline NEE75 & 0 & 0 & 0 \\
\hline NEE90 & 0 & 0 & 0 \\
\hline$N i 30$ & 0 & 0 & 0 \\
\hline $\mathrm{Ni45}$ & 0 & 0 & 0 \\
\hline$N i 60$ & 0 & 217 & 0 \\
\hline Ni75 & 0 & 0 & 0 \\
\hline $\mathrm{Ni} 90$ & 0 & 0 & 0 \\
\hline Xe30 & 0 & 0 & 0 \\
\hline $\mathrm{Xe} 45$ & 0 & 0 & 0 \\
\hline Хe60 & 0 & 0 & 0 \\
\hline$X e 75$ & 0 & 2 & 1 \\
\hline$X e 90$ & 2 & 2 & 0 \\
\hline$X 30$ & 0 & 0 & 0 \\
\hline$X 45$ & 0 & 0 & 0 \\
\hline$X 60$ & 2 & 10 & 5 \\
\hline$X 75$ & 0 & 0 & 0 \\
\hline$X 90$ & 0 & 1 & 0 \\
\hline E30 & 0 & 0 & 0 \\
\hline$E 45$ & 0 & 0 & 0 \\
\hline$E 60$ & 0 & 0 & 0 \\
\hline E75 & 0 & 0 & 0 \\
\hline$E 90$ & 0 & 0 & 0 \\
\hline$i 30$ & 0 & 0 & 0 \\
\hline
\end{tabular}
combination of two right triangles and rectangles so that when totaled for the vehicle the optimal results are 1295 car vehicles and for motorcycles there are 15440 motorbikes. Table 3 and Table 4 give an optimal decision of two types of vehicles.

Table 3. Optimal Car Table. 


\begin{tabular}{llll}
\hline \multirow{2}{*}{ Decision variable } & Landform & & Right triangle \\
\cline { 2 - 4 } & Parallelogram (direct) & Parallelogram (two right triangles and rectangles) & 0 \\
\hline$i 45$ & 0 & 0 & 0 \\
$i 60$ & 0 & 5 & 0 \\
$i 75$ & 0 & 0 & 0 \\
$i 90$ & 0 & 0 & 491 \\
Total vehicles & 1110 & 1295 & \\
\hline
\end{tabular}

Table 4. Optimal Motorbikes Tables.

\begin{tabular}{|c|c|c|c|}
\hline \multirow{2}{*}{ Decision variable } & \multicolumn{3}{|l|}{ Landform } \\
\hline & Parallelogram (direct) & Parallelogram (two right triangles and rectangles) & Parallelogram (direct) \\
\hline $\mathrm{Ne} 30$ & 0 & 0 & 0 \\
\hline $\mathrm{Ne} 45$ & 0 & 0 & 0 \\
\hline Ne60 & 0 & 0 & 0 \\
\hline $\mathrm{Ne} 75$ & 0 & 0 & 0 \\
\hline $\mathrm{Ne} 90$ & 1077 & 954 & 353 \\
\hline N30 & 0 & 0 & 0 \\
\hline N45 & 0 & 0 & 0 \\
\hline$N 60$ & 4907 & 0 & 0 \\
\hline N75 & 0 & 11620 & 5810 \\
\hline$N 90$ & 0 & 2701 & 0 \\
\hline NEE30 & 0 & 0 & 0 \\
\hline NEE45 & 0 & 0 & 0 \\
\hline NEE60 & 0 & 0 & 0 \\
\hline NEE75 & 0 & 0 & 0 \\
\hline NEE90 & 0 & 0 & 0 \\
\hline$N i 30$ & 0 & 0 & 0 \\
\hline $\mathrm{Ni45}$ & 0 & 0 & 0 \\
\hline$N i 60$ & 0 & 0 & 0 \\
\hline Ni75 & 0 & 0 & 0 \\
\hline$N i 90$ & 0 & 165 & 0 \\
\hline Xe30 & 0 & 0 & 0 \\
\hline Xe45 & 0 & 0 & 0 \\
\hline Xe60 & 0 & 0 & 0 \\
\hline Xe 75 & 0 & 0 & 0 \\
\hline$X e 90$ & 2 & 4 & 1 \\
\hline$X 30$ & 0 & 0 & 0 \\
\hline$X 45$ & 0 & 0 & 0 \\
\hline$X 60$ & 2 & 0 & 0 \\
\hline$X 75$ & 0 & 32 & 16 \\
\hline$X 90$ & 0 & 15 & 0 \\
\hline E30 & 0 & 0 & 0 \\
\hline E45 & 0 & 0 & 0 \\
\hline$E 60$ & 0 & 0 & 0 \\
\hline E75 & 0 & 0 & 0 \\
\hline$E 90$ & 0 & 0 & 0 \\
\hline$i 30$ & 0 & 0 & 0 \\
\hline$i 45$ & 0 & 0 & 0 \\
\hline$i 60$ & 0 & 0 & 0 \\
\hline$i 75$ & 0 & 0 & 0 \\
\hline$i 90$ & 0 & 1 & 0 \\
\hline Total vehicles & 11969 & 15440 & 6163 \\
\hline
\end{tabular}

\section{Conclusion}

From the discussion above it can be concluded that the optimal results of cars and motorbikes provide different results in each form of land. Optimal results for car vehicles with land in the form of parallelogram that is formed directly are 1110 vehicles, then the shape of the parallelogram is formed separately there are 1295 vehicles. These results indicate that the two forms are more optimal than the separated forms. Then, for the form of a right triangle gives optimal results 491 vehicle vehicles. The next vehicle is a motorbikes, the optimal result for motorbikes with land in the form of a parallelogram that is formed directly is 11969 vehicles, then the shape of the parallelogram is formed separately there are 15440 vehicles. Then, to form a right triangle give optimal results 6163 motorbikes vehicles.

\section{References}

[1] A. S. Abdelfatah and M. Taha, Parking capacity optimization using linear programming, Journal of Traffic and Logistics Engineering, vol. 2, no. 3, 176-181, 2014. 
[2] K. Abdullah, N. H Thursday, N. F. N. Azahar, S. F. Shariff, and Z. C. Musa, Optimization of the parking spaces: a case study of the Plains of Roses, UiTM Shah Alam, IEEE Colloquim on Humanities, Science and Engineering Research (CHUSER 2012), 3-4 December 2012, Kota Kinabalu, Sabah, Malaysia, 2012.

[3] G. Chang, and G. Ping, Research on parking space optimal design methods in parking lots, International Journal of Advancements in Computing Technology (IJACT), 5 (2013), 79-85.

[4] Director General of Land Transportation, Operation of Parking Facilities, Jakarta, 1996.

[5] F. S. Hillier and G. J. Lieberman, Introduction to Operations Research, Tenth Edition, McGraw-Hill, New York, 2010.

[6] I. Hasbiyati, W. Putri, A. Adnan, Ahriyati, and Hasriati, Parking lot optimization using the concept area of rectangular and right triangle, Pure and Applied Mathematics Journal, vol. $8,77-82,2019$.

[7] S. Munzir, M. Ikhsan, and Z. Amin, Linear programming for parking slot optimization: a case study at Jl. T. Panglima Polem Banda Aceh, Proceedings of the 6th IMT-GT Conference on Mathematics, Statistics and its Applications (ICMSA2010) Tunku Abdul Rahman University, Kuala Lumpur, Malaysia, 2010.
[8] N. K. Oladejo and B. D. Awuley, Application of linear programming in optimization of parking slots: a case study of Tamale-Bolgatanga lorry station in Ghana, International Journal of Emerging Technology and Advanced Engineering, $147-154,2016$.

[9] H. Siringoringo, Operational Research Engineering Series. Linear Programming. Publisher Graha Ilmu. Yogyakarta. 2005.

[10] I. Syahrini, T. Sundari, T. Iskandar, V. Halfiani, S. Munzir, and M. Ramli, Mathematical models of parking space units for triangular parking areas, IOP Conference Series: Materials Sciences and Engineering, 1-6, 2018.

[11] H. A. Taha, Operaions Research: An Introduction, Pearson Prentice Hall Eighth Edition, United States of America, 2007.

[12] W. L. Winston, Operations Research: Applications and Algorithms, International Student Fourth Edition, Belmont, 2004.

[13] M. Yun, Y. Lao, Y. Ma, and X. Yang, Optimization models on the scale of public parking lots, The Eighth International Conference of Chinese Logistics and Transportation Professional, 2692-2699, 2008. 